\title{
YOUTH EMPOWERMENT TOWARDS SOCIAL RESPONSIBILITY THROUGH SERVICE-LEARNING PROGRAM: AN EXPLORATORY ANALYSIS OF A PRIVATE HIGH SCHOOL IN DUBAI, UNITED ARAB OF EMIRATES
}

\author{
Roeia Thabet \\ roya95@gmail.com \\ $\mathrm{PhD}$ in education (International Management \& policy) \\ The British University in Dubai in association with the University of Birmingham \\ Universidad
}

Fecha de Recepción: 2 Abril 2018

Fecha de Admisión: 10 Abril 2018

\begin{abstract}
This study investigates student personal development and sense of social responsibility through a service-learning program in a private high school in Dubai-UAE. This study utilized a qualitative research approach with a single case study design to provide a rich and contextualized picture of the program from multiple perspectives (school leadership, teachers, service-learning team and students). Data was collected through triangulation by means of semi-structured interviews, focus groups, participatory and non-participatory observations, field notes, artifacts, and document analysis. Content analysis was used in analyzing the collected data to identify emerging themes and patterns related to service-learning and its effect upon students. The study's findings revealed that the school applied essential elements of service-learning. The participants of the service-learning program exhibited social responsibilities of greater community awareness, teamwork, commitment to community, gained self-esteem, and self satisfaction as they reflected on their ability to accomplish their tasks. This study's goal is to bring about educational policy pertaining to service-learning as a legitimate educational pedagogy to be adopted in the UAE schools. This study hopes to contribute to service-learning program research and enrich knowledge and best practices in the UAE and worldwide.
\end{abstract}

Keywords: service-learning; adolescents; education; social responsibility

\section{INTRODUCTION}

An urgent need for youth involvement in constructing society and contributing to a harmonious community has become a recent movement in the world and particularly in the Middle East. As the Middle East region is going through tremendous transition, a great need for social responsibility attitude is essential for creating a better society where every individual is playing a vital role in caring 
for others and understanding the value of social responsibility (Corps 2012). The majority of the empirical research in this area has unanimously identified common positive impacts on young students' personal and social development. While research provided mostly quantitative evidence that service-learning has multiple benefits for students, there was clear gap in the literature for more qualitative studies regarding both process and effects of the program in schools.

This research study's goal is to reveal rich information on how a service-learning program is applied within its known framework in a private high school in Dubai. This will shed light on the challenges and concerns that occur as the service component is linked and integrated to the UAE academic curriculum. There is a genuine need to investigate and review the newly applied service-learning program in a private high school in Dubai. The purpose of this study is twofold; the first is descriptive, which will focus on describing and exploring how private high schools (students ages 14 to 17 years old) in Dubai are fostering and carrying out the service-learning program. The second is to investigate the empowerment of students, through the act of service, with subsequent development of social responsibility that results from their contribution in their society. The purpose of this study is to examine the role of schools in developing students' personal and social responsibility.

The significance of this study is it will enrich service-learning literature by describing the application of a service-learning program through the UAE context. Although service-learning is valued as an active learning strategy across the globe, little is known concerning its similarities or differences within various contexts across cultures. This research is one of the few qualitative empirical service-learning studies. It is hoped that the study's results concerning the effects of service-learning and the empowerment of young students through social responsibility will assist other schools to understand the importance of implementing this program. The study also hopes to contribute to educational policy to enhance the program by developing more detailed strategies along with support for students and schools.

\section{LITERATURE REVIEW}

Many authors have utilized the theoretical framework of how service-learning promotes social and personal development in young students. This direct link was demonstrated and explained cohesively by Youniss \& Yates (1997), which is built on Erikson's (1968) theory of identity. They suggest young individuals attempt to search for their identity and develop ideologies and values, which ultimately affect their adulthood lifestyle. According to Erikson (1968), adolescence is the time that identity starts to shape one's personality resulting in their future adulthood identity.

During this remarkable stage of the human life cycle, adolescents experience rapid psychological and physical changes. For example, by the age of 12 signs of transition start and continue till the age of 15 or 16 . They will gain height, build muscles, and different hormonal changes in boys and girls start to shape their physical appearances. They will go through puberty acquiring physical changes. The physical developmental stage interrelates closely to psychological transition. They begin to experience mixed feelings of sensitivity, anxiety, and awkwardness, which might generate contradictions in one's behavior. Erikson describes this period of time the period of 'crises' (Erikson 1968; Kellough \& Kellough 2008). In an attempt to understand the meaning of students' interest in community service, this study builds its argument on Erikson's theory of identity formation as students establish their self-development within a collective social context.

Erikson (1968) refers to identity crises as the process that many adolescents go through to form distinctive features of their self-personality. They become fully aware of the need to form a meaningful identity that includes values, beliefs, history, and future objectives of life. This will take the 
individual to another stage called discovery that is linked to the philosophical concept of the true self. Individuals start to discover their potentials, capacities, values, and unique abilities that distinguish them from others and the ability to differentiate between right or wrong, etc.

This research study seeks to link the theory of identity development in students through a service-learning program and to explore the extent of its impact on students. It also emphasizes the extent to which the service-learning program affected the moral judgment of the participants by looking at specific elements and processes that led to the development of moral agency and sense of social responsibility towards society. Hence, the reason behind building this study's framework upon the theory of identity formation goes beyond the intention of understanding how identity is formed in adolescents. The main objective is to understand what constitutes a noble and meaningful identity that reflects social responsibility.

\section{HISTORICAL BACKGROUND OF THE SERVICE-LEARNING PROGRAM}

The philosopher John Dewey (1916) was one of the first educators to introduce the concept of connecting schools to communities through service. He believes that the goal of an educational curriculum system is to link to students with the community to meet the needs of society and its social welfare (in Arenas, Boswortha, \& Kwandayib 2006). Dewey's theory of linking school life to the surrounding environment called for a new form of pedagogical approach called 'service-learning'. However, Dewey takes this concept deeper than mere application of academic learning to a higher level of human interaction to contribute in social life. He perceives schools as social institutions that create venue for social reform rather than mere learning institutions. As a result, students flourish in an environment where they are provided opportunities to experience and interact with the curriculum within the social context. Building on Dewey's theory, Counts (1932) stresses that education should prepare students to become agents of change and build their society through their skills, knowledge, values rather than to become selfish consumers.

\section{DEFINITION OF 'SERVICE-LEARNING'}

The name service-learning program is defined as a "pedagogical approach that integrates community service with academic study to enrich learning, enhances social responsibility, and strengthens communities" (National Service-Learning Cooperative 1998). The main differences between service-learning and community service is that service-learning is a method, which combines curriculum objectives and standards with community service for students to carry out service projects that meet real community needs. On the other hand, community service primarily focuses on applying service projects in the communities with no direct link to curriculum objectives and doesn't necessarily involve intentional or prescribed learning goals (Edwar 2002).

\section{ESSENTIAL QUALITY OF SERVICE-LEARNING PRACTICE GUIDELINES}

The Essential Quality of Service-Learning Practice Guidelines developed by National ServiceLearning Cooperative (1998) guided this study to explore the application of the program in the UAE context.

The Essential Quality of Service-Learning Practice Guidelines were developed as a result of a series of studies and examination for the past decade to understand why some service-learning programs were able to achieve positive outcomes on some students compared with other students either within the same school or others (Billig 2000). The guidelines included linking Classroom concepts to service-learning activities, students' voice in planning, executing the projects, and evaluation through reflection methods. 


\section{OUTCOMES OF SERVICE-LEARNING PROGRAM}

A body of research studies conducted over the past decade reported positive outcomes of a service-learning program on students' personal, social, and cognitive development. Findings found that participating students in this program gained: self esteem, confidence, sense of commitment to society, long-term engagement in community service, developed moral attitudes (respect for others), empathy, justice, sense of caring for others, teamwork and self-efficacy (Conrad \& Hedin 1982; Newmann \& Rutter 1983; Moore \& Sandholtz 1999; Muscott 2000; Steinberg, Bringle \& Williams 2010).

Youniss and Yates (1997) report that almost all the graduated students in his study research continued engaging in voluntary and civic acts of service in various forms, while others demonstrated deeper understanding and feelings of social relatedness, empathy, and care for others. They concluded that exerts from the graduated students after 6 years, illustrated that as individuals move beyond adolescent into adult life they often maintain continuity with their past. The participants were involved in activities during the crucial period of identity development, which guided them with meaningful objectives in their lives (p. 128).

\section{SERVICE TO COMMUNITY IN THE UAE CONTEXT}

On the local level, the UAE recently started encouraging schools and students to be involved in a community service program and urged schools to prepare programs in their educational system to engage students in serving the society (Al Bayan 24 April, 2014, p.7) and (Al Khaleej 22 December, 2013). The Ministry of Education and Human \& Development Authority (KHDA) inspection standards share the important role of Social Responsibility in the UAE Vision 2021.They emphasize the role of schools in developing students' personal and social responsibility in the UAE context.

School inspection reports published by Knowledge and Human Development Authority (KHDA) in Dubai indicate that many private schools provide opportunities for students to carry out community service programs for involvement in society's affairs (Knowledge and Human Development Authority 2013). These reports indicate the existence of these activities in schools. The KHDA school report attempts to assess schools based on criteria that include 'students' personal and social development'. There is little known about the quality of the service programs, the extent of students' participation in UAE private schools, and the program's impact upon students' sense of social responsibility. The school reports include brief descriptive paragraphs of service programs carried out by schools. This study intends to investigate this important element in high school students.

\section{METHODOLOGY}

\section{Research Design}

Most service-learning quantitative studies provided consistent evidence of the positive impact of service-learning on students' personal development and sense of social responsibility. There are some researchers that consider it an imperfect approach, as it is a complex to evaluate students' perspectives. This created a clear need for more qualitative studies to bridge this existent gap in research (Hamilton \& Fenzel 1988; Conrad \& Hedin 1981; Billig 2000). Thus, this study adopted qualitative approach to bridge this gap in the literature to generate new knowledge in the field of service-learning research. It adopted an embedded single case study design to examine the application of a service-learning program in a particular school in Dubai. The subunits include the investigation of the process of application by the school management, service-learning team, teachers, and students. This includes more subunits of the investigation of each unit as well. For example, the 
unit of school management includes understanding the vision, mission, and policy regulation related to a service-learning program, while the service-learning team unit includes reviewing their training and preparation materials. It builds upon the teachers' unit of lesson plans, activities, and class observations. It also includes the students' unit of written reflective feedback, planning, and application details of the service-learning projects in the field.

\section{Site Selection}

A high private school in Dubai was selected. Care was taken in selecting the school to answer the research question and add rich-information to the service-learning research worldwide. The selection of the site was based on schools that apply a more intensive service-learning experience, which the program's application utilized the same term 'service-learning program'. The selected case study school is located in the Deira area in Dubai and offers K-12 education for 2,682 students and 1,802 are Emirati local students. Hence, the largest nationality group students are Emirati nationals. The school offers both American and Ministry of Education (MOE) curriculum that provides students with the choice to select their curriculum preference. This study was conducted in the American curriculum section since a service-learning program was applied only in that section. The school follows gender segregation system in which boys and girls are segregated into separate sections within the same school starting from grade 6.

\section{Participants}

Purposeful sampling was applied in selecting participants who actively were engaged in servicelearning program over one academic year to provide rich information related to the purpose of the study. Participants were selected for this study based on four levels to answer the research questions and provide rich information for this study: The first level is the school management, which includes the principal and school administration. The second level is the service-learning team, which includes the team leader and the service-learning coordinators. The third level includes participants' teachers in the service-learning program, and the fourth level is participating students in the program who are the core of this study. This study selected students that were involved in service-learning projects with the same teachers for one whole academic year to be part of students' focus group interviews.

\section{Data Collection and analysis Methods}

An interpretative tradition was adopted by this study to make sense of participants' perceptive, interpret their meanings, to analyze the training materials and students' written feedback. This research used a single case strategy with the goal of providing a rich, contextualized picture of the phenomenon under study. Data was collected using qualitative methods of semi-structured interviews, focus groups, participatory and non-participatory observations, and artifacts related to the context of service-learning application. Moreover, document review method was considered one of the important methods in data collection of this study, which included: UAE strategic plan, KHDA inspection reports, newspaper articles, students' written reflective feedback, training materials, action plan, teachers' time table, SL team leader reports, students' presentation documents, and orientation documents. Provisions for trustworthiness were incorporated within the study through triangulation by employing multiple data collection methods and examining participants' perspectives from various means. In addition, other provisions included prolonged engagement on site and member checking. Multi-methods were used in analyzing interview transcripts, photographs, observations, documents and field notes depending mostly on Miles and Huberman's (1994) guidelines. These steps included data management, reading, memoing, and coding. All interview transcripts, 
observational notes, and students' reflective feedback were coded and analyzed, which were followed by presenting and displaying data. Students' reflective feedback documents were processed and displayed in a matrix design as recommend by Miles and Huberman (1994) to facilitate interpretation. Accordingly, the interpretation phase included lessons learned and insights from analyzing data through a descriptive analytical approach. The collected data was analyzed based on content analysis approach using a coding and thematic system. In brief, 6 interviews were conducted that included school leadership, teachers and a service- learning coordinator. Total 6 focus groups including 56 students from grade 9-12 for both girls and boys. In addition 79 written reflective feedback papers were collected as well as 15 observations were conducted.

\section{FINDINGS}

Results presented in this section sought to answer the first research questions: How a servicelearning program is applied in a private high school in Dubai?

The historical development of the service-learning program evolved over the span of years from a school-based community service program to a service-learning program due to several shortcoming of the program. The school applied a service-learning program from the beginning of the academic year 2014-2015 incorporating many elements of quality service-learning practices. The process and strategies were applied on three main levels:

1. On the level of school management and teachers. This level included a short presentation about service-learning to the school principal to illustrate the main vision and objective of the program. This was followed by teachers' orientation and request for voluntary participation in adopting the program. Then, teacher's training sessions were held for the nominated volunteered teachers followed by expansion of the service-learning team to support and accompany teachers. Modifying teachers' schedules and school timetable was another vital process adopted by the school management. Moreover, teachers and students engaged actively in the service-learning celebration and the school management supported all the financial cost of the celebration.

2. On the level of students: As for this level, many of service-learning essential elements were followed, such as allowing students' voice in suggesting, planning, and applying service-learning projects. Prior to this stage, series of students' workshops were carried out to prepare them for social responsibility toward society. It explained the aims, objectives, and process of the program. In addition, students played a vital role in the preparation of the program celebration to present their projects to parents and community partners.

3. On the level of service-learning team: Service-learning team followed a series of strategies and processes to support teachers and students. For example, they prepared the component of the program, which consisted of training materials for teachers and students. They conducted orientations for parents, developed partnerships with relevant social agencies, organization, and community partners. They also played a vital role in accompanying and assisting individual teachers in their class and service field. Moreover, developing an evaluation system and action plan was part of their responsibility in this program. Evaluation of the service-learning program was derived from three sources. The first was from students' self report, which included their reflective feedback, presentation of their activities, artwork, and their active involvement in the program. The second was derived from teachers' feedback in teachers' reflective meetings through constant verbal discussions with service-learning team. The third was based on service-learning team members as each accompanied several teachers throughout the year in all the program's phases. Accordingly, they witnessed all types of challenges and achievements of teachers and students while in the field with them. The school applied essential service-learning elements. These included service projects linked to the cur- 
riculum, duration and intensity of project, reflection, students' voice, partnership with community agencies, evaluation of students, and the program as a whole. The following section focuses on answering the second research question: To what extent does a service-learning program contribute in students' personal development and sense of responsibility?

\section{Change of Preconception Perspectives}

Many students commented on gaining new perceptions after they engaged in their service-learning projects. They clearly admitted their preconception changed once they entered the real life field and interacted with people in various contexts. For example, some students commented in the focus groups: "We were shocked to find out that there are many people live like this and have many social issues".

Similar comments were shared by a student in grade 12, which was repeated by her peers in the focus group. This indicates the extent of the impact on students' preconception views once they interact in real social contexts:

As for me, before this project, I did not know much about children's right, I consider them regular small children who don't understand anything in life and once they grow up they will have rights as their understanding develops. However, I was wrong and was surprised when I saw how smart and articulate they were. For example, I came across children who amazed me by their strong personality and inelegance as they were talking to us. I really imagined that in the future they would hold important positions. I can now say that my perspective totally changed about children. Now I am certain that they have rights and they actually make an important part of our society.

\section{Self Esteem and Confidence}

Many students described feelings of accomplishment and satisfaction because they were able to interact with others, help, bring joy and happiness to the people they served. As a result, they did feel confidant and developed self-esteem. It was noticed that most students used similar phrases or words to describe their feelings in gaining self-esteem in their written feedback and interviews. For example, one of the students said: "I learned that I could be a helpful person in the future. I understood that my role is important and so are the others too. I am capable of helping anyone."

Many teachers reported that their students changed over time especially after they engaged in the application of service-learning projects. Some teachers expressed their astonishment as they observed their students gaining confidence in talking with others and transforming from being shy students to speaking in public. They also commented that their students consulted and supported each other in the field. The following are some comments from teachers' reflection meeting accounts in which teachers shared their experiences with each other.

I really thought that these students would not change at all. However, after our first project, despite of many challenges, I really saw few of them who participated in the program, became more confident. For example, I had a student, whom I never heard his voice, never participated in any activity in the class, he was always a quite boy, but during service-learning sessions, he was the most active student in the entire class. I was truly shocked to see him, suggesting, discussing, planning and applying. I couldn't believe my eyes when I saw him presenting in the class as part of the project.

\section{Sense of Joy and Teamwork}

Sense of joy and teamwork was interrelated in students' responses. Many students expressed great sense of joy in two contexts. The first in the context of carrying out service projects as they interacted with people and tried to help them understand their issues, etc. The second was in the 
context of joy in working in groups and developing a sense of teamwork. Some students commented on their service-learning project:

At first we were so afraid and shy to enter the center and talk to people, but after a while we became courageous and confident. We also realized that because we were in one team, we felt comfortable as we depended on each other and supported each other in the project.

Another group of students said:

The success of our projects were mainly because of the strong teamwork, we respected each other's suggestions and learned to consult about everything."

"I learned the importance of teamwork. I think that it doesn't matter how big or complex is your project is because the important thing is how you cooperate together in one team.

\section{Development of Knowledge and Skills}

Students reported that they developed knowledge and skills throughout the projects. Feedback included their knowledge of community's issues increased as well as global issues. Moreover, the enhanced knowledge of their surrounding was expressed through self-investigation, research, preparing presentations, public speaking to raise awareness among their school members and in their community. They also developed skills of planning, consulting, time-management, and communication with community agencies. In addition, their knowledge and skills went beyond mere acknowledgment of the certain issues to expressing a desire to carry out actions to make a change though it might seem small and insignificance. Below are some extracts from students' interview:

By preparing an awareness campaign, which included a seminar and a dialogue with women in our society, I felt that I was part of a campaign that aims in preventing this injustice to happen in our society. Through this project we learned how to educate our society for not preventing women from their rights. I felt that I made a change in my community.

Some students reflected on heir service-learning project as they prepared for awareness campaign regarding women's rights:

At first it was challenging to prepare questions to ask our parents as we were not sure if our question would offend them. We consulted a lot and changed many questions until we decided on few questions. However, the discussion part went fine and we learned now how to prepare for better seminars and what questions we should ask to start discussions without offending anyone.

\section{Students' Sense of Ownership}

In response to the research question of understating the process of applying service-learning program in a school, part of this question was answered through student's replies of how they carried out their service-learning projects. Most of the students' responses indicated their ownership of the project, as they wrote in detail in their reflective feedback and talked thoroughly in their focus group interviews about their project application. They also were able to reflect on the steps and the process of their projects from the beginning till the end. On the other hand, teachers' responses corresponded with student's themes in which they observed that students changed their attitudes towards learning to develop investigative skills. Some teachers commented that they were so surprised that some of their students participated in discussions, planning, giving suggestions for their service projects, and more surprised by their involvement in carrying out the projects. A teacher commented:

I really expected that the students would not take it seriously, walk around, and would show immature behavior towards children, but my expectation changed totally during the project. I was surprised and astonished in seeing the students act seriously. They came well prepared and were 
treating the children with kindness and patience. I noticed they praised the children, and behaving in a way that is really amazing for me. What I observed was beyond my expectations.

\section{Development of Sense of Social Responsibility}

Most of the responses indicated that a sense of responsibility developed in students due to their acknowledgements of their moral behavior that they acquired throughout the program.

Long- term engagement: Most of the students, who actively participated in the service-learning program in the first semester constituted with more confidence in the second semester and showed stronger commitment. The majority of them expressed their desire to continue serving their community. One of the teachers stated:

I really saw how happy the students were after applying the first project. Some of them came to me and asked many times, "when will we do a second project? We want to do more". I really was glad to see them eager to plan for projects for the community.

Strong connection to community. Students reported a strong connection to their community to help and make changes after reflecting on their experience and entering the reality of others. They felt responsibility towards their society.

On student said: "We are the citizens of this country and it's our responsibility to help people and give ideas to build our society."

Another student from the same class commented:

"I understood the feelings of people who have problems and tried to help them by finding solutions for them."

\section{Empathy and Compassion}

Some students expressed empathy and compassion towards certain situations they encountered and towards some people they met during their service project. Feelings, such as sadness and disappointment followed by their desire to do something about it were quoted often in their response. This indicates that through their involvement in planning and carrying out service projects they were able to develop awareness of the community. They realized that there are various realties in the world other than their own reality, which they are not aware of until they got involved directly in the field. However, taking action to change the situation was not in all the students' responses. Some of them felt that it is not a responsibility of one person to change but the entire society including its intuitions.

It is noticed through analyzing students' responses that compassion was the main trigger to start reflecting on their own preconception thoughts and creating a sense of community involvement. Recurring themes emerged while analyzing the collected data, which included greater community awareness, teamwork, commitment to community, increased self- esteem, and self-satisfaction as they reflected on their ability to accomplish their tasks. The Students demonstrated acquisition of moral characteristics such as, care for others, respect and empathy, joy and happiness in applying service projects.

\section{Service Learning Team as Role Models}

One of the key findings in this study was analyzing the role of the SL team including the team leader as they were considered the main engine of the program. First of all, the three members of the SL team were role models for the program not only for students, but also for teachers and school management. The SL team consisted of active members in the community service program. Their knowledge and field experiences in voluntary and service activities enriched the program, which they established relationships with social and government organization to provide opportunities for stu- 
dents to carry out their service projects. Their commitment to volunteer to facilitate the servicelearning program in the school was an example of the teachers, students, and school management believing in voluntary community service along with striving to make a difference in the society.

\section{DISCUSSION}

This study provided strong empirical evidence on applying most of the essential quality elements in service-learning and adding few into these elements as the program evolved during one academic year in this school. Most interestingly, many of these essential elements were adopted due to intensive consultation and reflection between Service-learning team, school leadership, and teachers.

\section{Development of a Structured Program}

The school applied an organized structure for the service-learning program that was aligned with the literature review. In general, the findings of this study revealed that one of the most significant steps undertaken by the program was to develop a structured action plan. It was not rigid, which allowed for changes and modification throughout the year. This structured action plan provided clear vision for teachers and students to understand the objectives and outcome of the program. Through developing an action plan based on essential quality elements of a service-learning program, this process helped all participants in the program to understand the big picture of the program.

\section{Consultation, Action, Reflection}

'Consultation, action, and reflection' was one of the themes that emerged during analyzing the findings from various dimensions. This approach was adopted in different settings, phases, and among all the participants. For example, the SL team leader always consulted with the school principal from the beginning of the program till the end of the academic year concerning every step of the program. These steps included, nominating teachers, students and teachers' preparation, time tables, school calendar, and spreading awareness of the program in the school, etc. Moreover, the SL team leader reflected with the school principal and updated her after applying each phase in the program reflected upon the challenges, achievements, and analyzed the outcomes. She consulted about overcoming obstacles that the program faced and this cycle of consultation and reflection continued in all the phases. This process of 'consultation, action, reflection resulted in reviving the program rather than developing a rigid system that doesn't allow a chance for modification. However, it doesn't mean that the program was carried out from random un-organized activities, but it preceded a constant rhythm of consultation, action, and reflection. Hence, it can be noticed that the program was propelled by a framework and then expanded based on collective gained experiences believing that each context has its own unique needs.

\section{Exploring Moral Identity through Action}

Many students expressed their gratification for having the opportunity to perform acts of service in the community as they felt some emptiness in their lives. When they were asked about their opinion of a service-learning program in their school, some students reported that they always wanted to perform community services, but they didn't know how and where? Erikson and Dewey could closely link this insight to the theory of identity formation in this particle stage in adolescents' life as described. Based on evidences derived from teachers and students' interviews in this study; some students who were labeled as inactive, shy students, or non-participative students in class, showed remarkable participation in service-learning projects. The analysis of collected data found some changes in students' perceptions about race, social class, gender, and religion as they engaged in 
service projects in their community. This implication was interrelated with their expression of feelings of empathy. Furthermore, many students from various classes repeated one term "we are all on" after engaging in different service projects with various people in their community. Likewise, LeSourd (1997) emphasizes the impact of community service on students' acquisition of deeper human virtues.

\section{Increase in Sense of Social Responsibility}

In this study, one of the main advantages of a service-learning program, as expressed by many students, was the realization of their capacity to conduct acts of service and helping others in their community through direct interaction with people. Many students repeatedly expressed feelings of pride in their ability to 'make the change' after carrying out service projects. These findings indicate that students were able to discover their potential, which in this sense refers to their identity as individuals who can make a positive change through practical service projects. According to Erikson's theory (1968), discovery of one's self-potential starts to form during the stage of adolescence through meaningful social interactions. Moreover, signs of compassion, empathy, and concerns for others' wellbeing were clearly evident in students' transcripts and reflective feedback accounts as they acknowledged the needs of others.

\section{Beyond Meeting Mere Curriculum Outcomes}

Consistent with the literature, this study presents evidence of new learning experiences that were acquired by students beyond theoretical academic objectives. For example, some students expressed their new realization of the role of teacher and their hard work for one full school day. Their academic lesson was about The Teacher who made a difference in students' lives and they had to plan for a service project relating to their lesson. Upon reflecting on their feedback, it was noticed how they tackled other aspects of a teacher's life. They described the attributes that they developed throughout their experiences, such as patience, love, sincere love and kindness, the importance of proper preparation, the amount of work to preparer one lesson, and the importance to be a role model for their students as they look up to them. At first, students were able to reflect on the attributes and skills that they developed, but later they associated their leaning experience to the role of their teachers and resulted in expressing their appreciation of their hard-work and commitment to change their behavior in class as a token of appreciation. This means that the service project met the required pre-determined outcome objectives of a lesson to understand the role of teachers in students' lives. It went beyond that as students encountered other aspects of teachers' life characteristics that they hold, and actual process of their work. Various dimensions occurred during the project, such as developing communication skills, moral behavior, and discussion of the detailed work of teaching career.

\section{Feelings of appreciation and contentment:}

Students reflected on their lives and attitudes as they interacted with people in the community. They realized they were taking their better-off life for granted, as well how blessed they were by being surrounded with loving family and friends. In addition, feelings of gratification and appreciation were expressed throughout their transcript and reflective feedback towards their teachers. For example, one of the service projects that some students carried out included playing the role of teachers for one school day. Students reported intense feelings and reflected on the role of their teachers in their lives. 


\section{SERVICE-LEARNING PROGRAM CHALLENGES}

In general, challenges that faced this school are categorized into three main categorizes, challenges that faced the teachers, students, and the service-learning team. The challenges included teachers' workload, difficulty in connecting community service with curriculum objectives, teachers' dropouts and withdrawal, late responses from social and service provider agencies as well as lack of cooperation and support by subject department coordinators. Some teachers faced difficulties in addressing the needs of all their students in their classes as students' motivation to engage in the service-learning program varied. Some students were eager to offer suggestions, actively participate, and provide commitment during and after applying service projects. On the other hand, some students did not show any interest during the service-learning sessions, and aimed to distract the class in addition to being absent during the application of the projects in the field.

Another challenge included lack of students' prior involvement in any community service activities. This challenge contributed negatively during the application part of the program, as many students offered suggestions and an action plan during their sessions to allow students' voice and ownership. Lack of information concerning social agencies, institutions, government organizations, and the nature of role and responsibility of those agencies added more responsibility for teachers and the SL team. They had to find various methods to raise awareness in students and to trigger discussions

\section{RECOMMENDATIONS}

The results of this study provided many significant insights to realize that adopting and applying service-learning program cannot be achieved only by schools' efforts. These findings suggest policy implication for applying a service-learning program to be fostered in schools on various levels as well. They are as follows:

Institutionalizing service-learning program in schools. There is an urgent need for decision makers and educators to recall the purpose of education, and its intended outcome to be obtained by students. Throughout the past few decades, studies reveal consistent results of the impact of a service-learning program on students' personal development and enhanced social responsibility. In addition, it also produced evidences for its effectiveness in enhancing academic abilities although it was not discussed in this study.

Starting Service-learning Dialogue. This study recommends starting with dialogue concerning a service-learning program on different levels. These would include many forms, such as conferences, seminars, and orientations to raise awareness and understanding about the significance of the program. These dialogues should strive to expand the public discourse about the importance of youth in terms of their identity development, their positive characteristics, and the belief they have the potential to be active citizens in their society.

Integration of service-learning into the education process. Findings from this case study indicate that if it wasn't for the school principal's personal belief to find ways to motivate students to play a vital role in society, a service-learning program was not to be applied. There were no clear guidelines, nor emphasis by policy leaders to link academic learning to community service other than highlighting the role of school to promote community service in its general context in the UAE schools. Thereof, based on this argument, this study suggests issuing official requirements for schools to strive to apply a service-learning program as an integral component in its educational program. This would include the development of assessment and multiple evaluation methods to assess the impact of the program and to develop it further.

Furthermore, recommendations include addressing various dimensions of the education system 
such as, developing a support system for schools, enhancing teachers training programs, sharing learning experiences revising / modifying curriculum objectives and outcome as well as enhancing community partnership.

\section{CONCLUSION}

Findings of this research study suggest that a service-learning program enhanced to some extent sense of social responsibility and personal development in students. The findings support the view that a service-learning program, in its various forms and structure, provide rich and valuable opportunity for students to develop identity that revolves around social responsibility. This study indicates that many students often reported that through their participation in service-learning project they acquired many values and personal attributes that helped define their sense of identity. In evaluating the outcome of service-learning program on students' personal development and social responsibility, it is useful to make the distinction between impact as an immediate measurable change, and process of gradual change in students as well as individual and collective change. Consequently, service projects related to curriculum produced far more outcome than predicted outcome determined by the curriculum objectives. Through the combination of these two, students gained clarity about their self, aspirations, moral attributes, and enhanced their understanding of the connection between needs of their community and their role in addressing them. In sum, these findings not only reinforce much of what is already known in the literature, but also, add a more in-depth descriptive first-hand account from participants' perspective of service-learning program in their school.

To this point, findings of this study supported adolescent theories that emphasize the importance of providing a special platform and environment for students to form 'meaningful' identity, and discover their moral attributes once engaged in structured social programs. Community service projects are not considered end results; rather it is only one process among a series of other process to help young students analyze, reflect, develop sense of social responsibility, and care for others. Therefore service provision is not seen as ends, but as an important step towards understanding the concept of service as an overall social structural change, which requires more complex and longterm vision and dedication. This means that in order to develop these attributes in young students, they should go through an intensive, complex, and long process program rather than one fast shot of short term event with a tick-mark that they obtained their required service hours. Through exercises of these two elements (learning and serving) in a school life, it is hoped that this program will engrave in young students, in the long term, a meaningful and noble aspiration, in which they will strive to contribute positively to local and global affairs through their knowledge and skills.

\section{REFERENCES}

Al Bayan (214). Shikha Bint Seif Emphasizes on the Importance of Encouraging Students in voluntary work.

Al Khaleej (2013). Voluntary work in the UAE: the Reality, challenges and Recommendations. [on line]. [Accessed 4 September 2014] Available at: http://www.alkhaleej.ae/alkhaleej /page/5c49cdc2-b0d4-4a8e-864a-6b280c67dee7.

Arenas, A.A., Boswortha, K., \& Kwandayib, H. (2006). Civic Service Through Schools: An International Perspective. British Association for International and Comparative Education. Routledge, vol. 36, (1), pp. 23-40.

Billig, S.H. (2000). Research on K-12 School-Based Service Learning: The Evidence Builds. RMC Research Corporation, Denver, C0. [online]. [Accessed 1 June 2014] available at 
http://www.educationreporting.com/resources/CLP_Billig_article.pdf

Conrad, D.E., \& Hedin, D. (1981). National Assessment of Experiential Education: Summary and Implications. Journal of Experiential Education, vol.4 (2), pp. 6-20.

Conrad, D.E., \& Hedin, D. (Eds.). (1982). Youth Participation and Experiential Education. Journal of Child and Youth Services, vol. 4(3/4), New York: Haworth. pp.156.

Corps, M. (2012). Civic Engagement of Youth in the Middle East and North Africa: An Analysis of Key Drivers and Outcomes [online]. Mercy Corps. [Accessed 10 June 2014]. Available at: www.civicenterprises.net.

Counts, G.S. (1932). Dare The Schools Build a New Social Order. New York. The John Day Company.

Edward, B. F. (2002).Learning in Deeds. The power of Service -learning for American School. A Report from the National Commission on Service-Learning.K. Kellogg Foundation, [online]. [Accessed 10 October 2015]. Available at http://www.learningindeed.org.

Erikson, E. (1968). Identity, youth, and crisis. New York: Norton.

Hamilton, S. F., \& Fenzel, M. (1988). The Impact of Volunteer Experience on Adolescent Social Development: Evidence of program effect. Journal of Adolescent Research, vol. 3 (1), pp. 65-89.

Kellough, R. D., \& Kellough, N. G. (2008). Teaching Young Adolescents: Methods and Resources for Middle Grades Teaching (5th ed.). Upper Saddle River, NJ: Pearson Merrill Prentice Hall.

Knowledge and Human Development Authority (2013). Annual Report: The Performance of Private Schools in Dubai. Dubai Schools inspection Bureau. [online]. [Accessed 1 June 2014] available at http://www.khda.gov.ae/CMS/WebParts/TextEditor/Documents/KHDA\%20annual\% 20report\%202013_english.pdf

LeSourd, S. J. (1997). Community Service in a Multicultural Nation. Community Service Learning, vol. 36(3), pp. 157-163.

Miles, M. \& Huberman, A.M. (1994). Qualitative data Aanalysis. Thousand Oaks, CA,

Sage Publications.

Moore, K.P., \& Sandholtz, J.H. (1999). Designing Successful Service learning Projects for Urban Schools. Urban Education, vol.34(4), pp. 480-498.

Muscott, H.S. (2000). A review and Analysis of Service-Learning Program Involving Students with Emotional/Behavioral Disorders. Education and Treatment of Children, vol. 23(3), pp. 346-368.

National Service-Learning Cooperative (1998). Essential Elements of Service-Learning. St. Paul, MN: National Youth Leadership Council.

Newmann, F.M., \& Rutter, R.A. (1983). The Effects of High School Community Service

Programs on Students' Social Development. (Final report to the National Institute of Education,Washington, DC). Madison: Wisconsin Center for Education Research.

Steinberg, K.S., Bringle, R. G., \& Williams, M. J. (2010). Service-learning Research Primer. Scotts Valley, CA: National Service-Learning ClearingHouse [online]. [Accessed 15 June 2014]. Available at: http://servicelearning.gov/filemanager/download/Service-Learning_Research_ Primer.pdf

UAE Vision 2021. (2010). UAE National Charter 2021 [online]. [Accessed 1 March 2010]. Available at: http://www.vision2021.ae/

Youniss, J., \& Yates, M. (1997). Community Service and Social Responsibility in Youth. Chicago: University of Chicago Press. 